\title{
SANS Study of Clustering of Charged Micelles in Aqueous Electrolyte Solution
}

\author{
A.J. Chinchalikar ${ }^{\dagger}$, V.K. Aswal ${ }^{\dagger}$, J. Kohlbrecher ${ }^{\dagger}$ and A.G. Wagh ${ }^{\dagger}$ \\ 'Solid State Physics Division, Bhabha Atomic Research Centre, Mumbai-400085, India \\ ${ }^{*}$ Laboratory for Neutron Scattering, ETH Zurich \& Paul Scherrer Institut, CH-5232 PSI Villigen, Switzerland
}

\begin{abstract}
Small-angle neutron scattering studies have been carried out for the charged micellar system of $50 \mathrm{mM}$ sodium dodcyle sulphate (SDS) and $50 \mathrm{mM}$ tetrabutylammonium bromide (TBAB) in presence of salts. The system undergoes clouding (turbid) at $0.75 \mathrm{M} \mathrm{NaCl}$. We show that clouding takes place as a result of clustering of micelles and the required attraction is modeled by the Baxter's sticky hard sphere potential. The clouding is also examined for different salts and is governed by the counterion condensation and dehydration properties of salts ions.
\end{abstract}

Keywords: Self-assembly, micelles, particle clustering, small-angle neutron scattering.

PACS: 82.70.Dd, 82.70.Uv, 83.85Hf

\section{INTRODUCTION}

The phenomenon of clouding is observed in many soft matter systems like proteins, micelles etc. and is used for the applications in the separation processes of petroleum, chemical and pharmaceutical industries. The clouding is observed with the appearance of turbidity in the solution and characterized by the temperature known as cloud point temperature (CP). ${ }^{1}$ The value of $\mathrm{CP}$ depends upon structure and concentration of both solute as well as additives. This phenomenon at elevated temperatures is well known for nonionic and absent for ionic (charged) micellar systems. However, recently it has been observed that the charged micelles may undergo clouding in the presence of large hydrophobic counterions with increasing temperature. ${ }^{2,3}$ For example, the anionic micelles of SDS with TBAB show the clouding with increasing temperature. The role of $\mathrm{TBA}^{+}$counterions is believed to be two folds to reduce the net charge on the micelles by adsorption and to provide temperature dependent attraction through bridging among the micelles for clouding. 4

The salting out effect by the addition of salt can be used instead of temperature rise to achieve clouding at desired temperature. The concentration of salt at which clouding occurs is referred as cloud salt concentration. Herein, the clouding on SDS + TBAB micellar system in presence of $\mathrm{NaCl}$ has been studied SANS. The effect of different salts of Hoffmeister series ( $\mathrm{NaF}, \mathrm{NaBr}, \mathrm{NaNO}_{3}, \mathrm{KCl}, \mathrm{CsCl}, \mathrm{Na}_{2} \mathrm{SO}_{4}, \mathrm{MgSO}_{4}$, $\mathrm{CaCl}_{2}$ ) on clouding is also examined.

\section{EXPERIMENTAL}

The measurements were carried out using SANS instrument at Dhruva reactor, BARC, Mumbai. The experiments were performed in the scattering wave vector magnitude $Q$ range of 0.02 to $0.35 \AA^{-1}$. 5 Some of the measurements were also performed at the SANS-I facility, Swiss Spallation Neutron Source SINQ, Paul Scherrer Institut, Switzerland ${ }^{6}$, to measure Q up to $0.002 \AA^{-1}$. Surfactant SDS and TBAB were obtained from FLUKA. All the salts used were of analytical grade. The samples were prepared in $\mathrm{D}_{2} \mathrm{O}$ instead of $\mathrm{H}_{2} \mathrm{O}$ in order to get better contrast and reduce incoherent scattering due to hydrogen. The samples were held in $5 \mathrm{~mm}$ thick quarts cells at room temperature $\left(30^{\circ} \mathrm{C}\right)$. SANS data were corrected for background and empty cell contribution and normalized to cross sectional unit using standard procedure. 


\section{SANS ANALYSIS}

The small-angle neutron scattering technique measures the coherent differential scattering cross section per unit volume $(\mathrm{d} \Sigma / \mathrm{d} \Omega)$. For a micellar system, $\mathrm{d} \Sigma / \mathrm{d} \Omega$ can be written as ${ }^{7}$

$$
\begin{aligned}
& \frac{d \Sigma}{d \Omega}=n\left(\rho_{m}-\rho_{s}\right)^{2} V_{m}{ }^{2}\left[\left\langle F^{2}(Q)\right\rangle+\right. \\
&\left.\langle F(Q)\rangle^{2}\{S(Q)-1\}\right]+B
\end{aligned}
$$

where $\mathrm{n}$ denotes the number density of micelles, $\rho_{m}$ and $\rho_{s}$ are respectively scattering length densities of micelles and solvent and $V_{m}$ is the volume of the micelle. $F(Q)$ is single particle form factor and $S(Q)$ is interparticle structure factor and governed by the interaction potential between the particles. $\mathrm{B}$ is constant that represents the incoherent scattering background. The data were analyzed considering the micelles as prolate ellipsoidal and interacting through Baxter's sticky hard sphere potential. ${ }^{8}$

The polydispersity among the micelles is incorporated by expressing the cross section as

$$
\frac{d \Sigma}{d \Omega}(Q)=\int \frac{d \Sigma}{d \Omega}(Q, R) f(R)+B
$$

where $f(R)$ is the size distribution of the micelles and calculated using Schultz distribution function.

The fitted micellar parameters are micellar dimensions, intermicellar potential, aggregation number and polydispersity. The aggregation number is calculated by the relation $N=4 \pi a b^{2} / 3 v$ where $a$ and $b=c$ are length the semimajor and semiminor axis and $v$ is the volume of single surfactant tail. The parameters in the analysis were optimized by the nonlinear least square fitting program.

\section{RESULTS AND DISCUSSION}

Figure 1 shows the variation of cloud point as a function of $\mathrm{NaCl}$ concentration for $50 \mathrm{mM} \mathrm{SDS}+50$ $\mathrm{mM}$ TBAB system. The $\mathrm{CP}$ of the micellar system increases up to $0.2 \mathrm{M} \mathrm{NaCl}$ concentration (region I) and thereafter decreases for higher $\mathrm{NaCl}$ concentrations (region II). The increase in cloud point in region I can be understood if the micellar size increases on addition salt. The increase in the micellar size will need more number of TBA+ counterions to bridge and hence the $\mathrm{CP}$ increases. The decrease in $\mathrm{CP}$ in region II is expected because of increase in the dehydration (salting out) property of the salt ions.

SANS data of $50 \mathrm{mM}$ SDS $+50 \mathrm{mM}$ TBAB system as a function of $\mathrm{NaCl}$ concentration at room temperature $\left(30^{\circ} \mathrm{C}\right)$ are shown in figure 2 . The cloud salt concentration of the present system is $0.75 \mathrm{M}$. The enhanced scattering in the low $\mathrm{Q}$ region with addition of salt prior to cloud salt concentration could be because of either increased micellar size or increased attractive potential among the micelles. The overall scattering intensity falls after cloud salt concentration and depends on the excess $\mathrm{NaCl}$ concentration over cloud salt concentration.

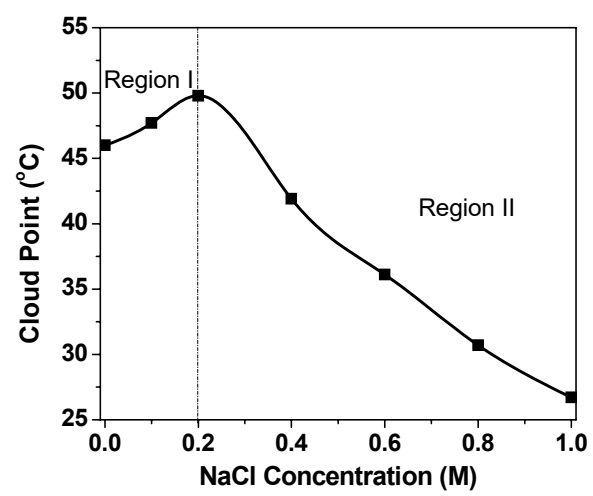

FIGURE 1. The variation in cloud point temperature (CP) of $50 \mathrm{mM}$ SDS $+50 \mathrm{mM}$ TBAB micellar system with increasing salt $(\mathrm{NaCl})$ concentration.

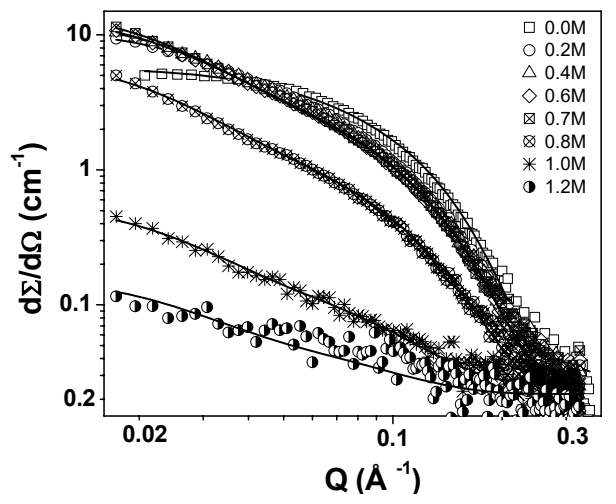

FIGURE 2. SANS data of $50 \mathrm{mM}$ SDS $+50 \mathrm{mM}$ TBAB micellar system with increasing salt $(\mathrm{NaCl})$ concentration before and after cloud salt concentration.

The fitted micellar parameters as given in table 1 show the increase in aggregation number as well as in attractive potential on approaching cloud salt concentration. The increase in the aggregation number is due to the counterion condensation of excess $\mathrm{Na}^{+}$ ions on an anionic surface of SDS micelles while the increase in attractive potential is due to the decreased Coulombic repulsion and the decreased solubility of $\mathrm{TBA}^{+}$counterions. The overall decrease in scattering intensity is a result of decrease in the number density of micelles because of conversion of micelles into clusters. The salt ions dehydrate $\mathrm{TBA}^{+}$counterions (salting out effect) which enhance the entropy driven hydrophobic attraction required for the clustering of micelles on clouding. The fraction of micelles on clouding decreases with increasing salt concentration suggesting both micelles and clusters coexist in the system. 
TABLE 1. Fitted parameters of $50 \mathrm{mM}$ SDS $+50 \mathrm{mM}$ TBAB with increasing concentration of $\mathrm{NaCl}$

\begin{tabular}{ccccccc}
\hline $\begin{array}{c}\text { NaCl } \\
(\mathbf{M})\end{array}$ & $\begin{array}{c}\text { Aggregation } \\
\text { Number } \\
\mathbf{N}\end{array}$ & $\begin{array}{c}\text { Semimajor } \\
\text { Axis } \\
\boldsymbol{a}(\boldsymbol{\AA})\end{array}$ & $\begin{array}{c}\text { Semiminor } \\
\text { Axis } \\
\boldsymbol{b}(\boldsymbol{\AA})\end{array}$ & $\begin{array}{c}\text { Shell } \\
\text { Thickness } \\
\boldsymbol{t}(\boldsymbol{\AA})\end{array}$ & $\begin{array}{c}\text { Potential } \\
\text { Depth } \\
\left(\boldsymbol{U}_{\boldsymbol{0}} / \boldsymbol{k} \boldsymbol{T}\right)\end{array}$ & $\begin{array}{c}\text { Volume } \\
\text { Fraction } \\
\left(\boldsymbol{\varphi}_{\boldsymbol{m}}\right)\end{array}$ \\
\hline 0.0 & 97 & 36 & 16.7 & 5 & -1.80 & 1.0 \\
0.2 & 204 & 106 & 16.7 & 5 & -2.0 & 1.0 \\
0.4 & 238 & 125 & 16.7 & 5 & -2.37 & 1.0 \\
0.6 & 253 & 133 & 16.7 & 5 & -2.68 & 1.0 \\
0.7 & 255 & 134 & 16.7 & 5 & -2.95 & 0 \\
0.8 & 269 & 140 & 16.7 & 5 & -3.10 & 0.4 \\
1.0 & 238 & 125 & 16.7 & 5 & -2.95 & 0.04 \\
1.2 & 236 & 124 & 16.7 & 5 & -2.92 & 0.02 \\
\hline
\end{tabular}

The limited $\mathrm{Q}$ range of the measurements in figure 2 do not show any significant scattering contribution from the micelle clusters because of their expected large sizes. Therefore the scattering from clusters is measured for low $Q$ values up to $0.002 \AA^{-1}$ on $50 \mathrm{mM}$ SDS $+50 \mathrm{mM}$ TBAB micellar system at $1.0 \mathrm{M} \mathrm{NaCl}$ concentration (figure 3). The $\mathrm{NaCl}$ concentration of $1.0 \mathrm{M}$ is selected as this system mostly consists of micelle clusters (table 1). The strong scattering in the low $\mathrm{Q}$ region is the Porod scattering from micelle clusters and indicates larger dimensions $(\sim \mu \mathrm{m})$ of clusters. The slope of the scattering profile in the low $\mathrm{Q}$ region is found to be $-4.8 .^{9}$ This deviation from Porod law may possible on account of the diffused boundaries of clusters and can occur due to variable scattering length density within the cluster. The non-uniform distribution of micelles can be the responsible factor for variable scattering length density within the cluster. The fitting of the data in the intermediate and high $\mathrm{Q}$ range provides about $4 \%$ of micelles remain in the solution.

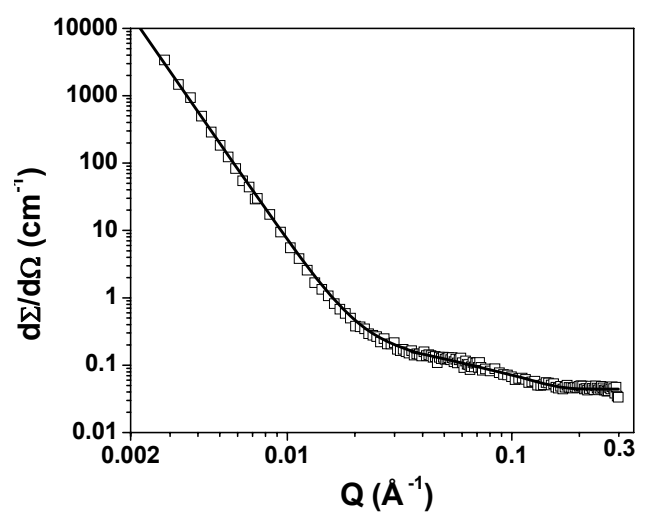

FIGURE 3. SANS data of $50 \mathrm{mM}$ SDS $+50 \mathrm{mM}$ TBAB at $1.0 \mathrm{M} \mathrm{NaCl}$ concentration

The effect of different salts of Hoffmeister series is summarized in Table 2. It gives the amount of salt required to bring the cloud point at room temperature. The order observed $\left(\mathrm{CaCl}_{2}<\mathrm{MgSO}_{4}<\mathrm{Na}_{2} \mathrm{SO}_{4}<\mathrm{NaF}\right.$ $<\mathrm{NaCl}<\mathrm{KCl}<\mathrm{CsCl}<\mathrm{NaBr}<\mathrm{NaNO}_{3}$ ) is a result of opposite roles played by the counterion condensation and water dehydration to control the cloud point. The variation in anions which only has dehydration effect shows the trend $\mathrm{Na}_{2} \mathrm{SO}_{4}<\mathrm{NaF}<\mathrm{NaCl}<\mathrm{NaBr}<$ $\mathrm{NaNO}_{3}$ and is consistent with the decreasing salting out effect of the salt . ${ }^{10}$ Both counterion condensation and dehydration become important in case of only cation variation. For example, the effect of monovalent cations $\left(\mathrm{Na}^{+}, \mathrm{K}^{+}, \mathrm{Cs}^{+}\right)$is in the order $\mathrm{NaCl}$ $<\mathrm{KCl}<\mathrm{CsCl}$ as decided by the micellar size depending on counterion condensation and dehydration $\left(\mathrm{Cs}^{+}>\mathrm{K}^{+}>\mathrm{Na}^{+}\right)$. The present study thus shows that addition of salt similar to that of increasing temperature can be used to tune the clouding in charged micellar solution.

TABLE 2. The cloud salt concentrations of various salts

\begin{tabular}{cc}
\hline Salt & $\begin{array}{c}\text { Cloud Salt Concentration } \\
\text { (M) }\end{array}$ \\
\hline $\mathrm{CaCl}_{2}$ & 0.15 \\
$\mathrm{MgSO}_{4}$ & 0.18 \\
$\mathrm{Na}_{2} \mathrm{SO}_{4}$ & 0.29 \\
$\mathrm{NaF}$ & 0.41 \\
$\mathrm{NaCl}$ & 0.75 \\
$\mathrm{KCl}$ & 0.79 \\
$\mathrm{CsCl}$ & 0.84 \\
$\mathrm{NaBr}$ & 1.61 \\
$\mathrm{NaNO}_{3}$ & 2.01 \\
\hline
\end{tabular}

\section{REFERENCES}

1. Y. Chevalier, T. Zemb, Rep. Prog. Phys. 53, 279-371(1990).

2. S. Kumar, V.K. Aswal, A.Z. Naqvi, P.S. Goyal, Kabir-ud-Din, Langmuir 17, 2549-2551 (2001).

3. B.L. Bales, R. Zana, Langmuir 20, 1579-1581(2004).

4. V.K. Aswal, J. Kohlbrecher, Chem. Phy. Lett.424, 91-96 (2006).

5. V. K. Aswal, P.S. Goyal Curr. Sci.79, 947-953 (2000).

6. J. Kohlbrecher, W. Wagner, J. Appl. Cryst. 33, 804-806 (2000).

7. J.B. Hayter, J. Penfold, Mol. Phys. 42, 109-118 (1981).

8. S.V.G. Menon, C. Manohar, K.S. Rao, J. Chem. Phy. 95, 9186- 9190 (1991).

9. G. Porod Kolloid Z 124, 83-104 (1951).

10. J.N. Israelachvili, Intermolecular and Surface Forces New York: Academic Press, 1992. 